UNIVERSIDADE DE SÃO PAULO

FACULDADE DE DIREITO

CURSO DE PÓS-GRADUAÇÃO

EMERSON ADEMIR BORGES DE OLIVEIRA

\title{
O IMPACTO DO CONTROLE DE CONSTITUCIONALIDADE NA EVOLUÇÃO DA DEMOCRACIA
}

Dissertação apresentada no curso de pósgraduação em Direito da Universidade de São Paulo, como requisito parcial para a obtenção do Título de Mestre em Direito (Área de concentração: Direito do Estado - Sub-área: Direito Constitucional).

Orientador:

Prof. Dr. Rubens Beçak 
EMERSON ADEMIR BORGES DE OLIVEIRA

\section{O IMPACTO DO CONTROLE DE CONSTITUCIONALIDADE NA EVOLUÇÃO DA DEMOCRACIA}

Dissertação apresentada no curso de pósgraduação em Direito da Universidade de São Paulo, como requisito parcial para a obtenção do Título de Mestre em Direito (Área de concentração: Direito do Estado - Sub-área: Direito Constitucional).

Orientador:

Prof. Dr. Rubens Beçak

SÃO PAULO

2013 
BORGES DE OLIVEIRA, Emerson Ademir

O impacto do controle de constitucionalidade na evolução da democracia / Emerson Ademir Borges de Oliveira; orientador: Rubens Beçak. São Paulo, SP: [s.n.], 2013

$164 \mathrm{f}$.

Dissertação (Mestrado em Direito) - Faculdade de Direito da Universidade de São Paulo

1.Democracia 2. Controle de constitucionalidade

CDD: 340.05 
BORGES DE OLIVEIRA, Emerson Ademir. O impacto do controle de constitucionalidade na evolução da democracia. 2013. 164 f. Dissertação (Mestrado em Direito) - Faculdade de Direito da Universidade de São Paulo, São Paulo, 2013.

\begin{abstract}
RESUMO
O princípio democrático está inscrito nas Constituições contemporâneas como fundamental para o desenvolvimento do Estado Constitucional. Embora o conceito possa variar, é certo que existem alguns pressupostos e características que permitem avaliar o status democrático de uma sociedade, bem como a existência de efetividade aos direitos diretamente decorrentes da democracia, vale dizer, direitos voltados à instrumentação do princípio. $O$ projeto constitucional se inscreve cotidianamente e passa a exigir o agir do Poder Público, em qualquer de suas funções, pois a efetivação da Constituição é dever de todos. Quando ausente a efetividade, passa-se a cogitar a transcrição dos direitos sobre a democracia pela veia constitucional. E ultrapassada a vertente meramente aplicadora da lei - concepção liberal da separação de poderes -, o Judiciário erege como criador do Direito em um aspecto interpretacionista. Surge, então, a discussão acerca dos limites da interpretação e das técnicas de controle de constitucionalidade para efetivação da democracia. Isto é, a discussão acerca do liame que separa a interpretação criadora da criação interpretativa, assim como o modo técnico-racional utilizado pelo Judiciário para realizar o princípio democrático. De qualquer forma, torna-se imprescindível a análise circunstanciada do modo de interpretação, até mesmo para que nunca se perca de vista o dever de racionalidade que deve permear a decisão jurisdicional. $\mathrm{O}$ objetivo não é negar o evidente processo criativo do Judiciário, mas entender seu funcionamento, de modo que seu exercício não exceda a interpretação razoável dos preceitos constitucionais.
\end{abstract}

Palavras-chave: Democracia. Controle de constitucionalidade. 
BORGES DE OLIVEIRA, Emerson Ademir. The impact of judicial review in the democracy evolution. 2013. 164 s. Thesis (Masters in Law) - Faculdade de Direito da Universidade de São Paulo, São Paulo, 2013.

\begin{abstract}
The democratic principle is present in the contemporary Constitutions as the central for the development of the constitutional State. Although the concept may vary, there are some assumptions and characteristics that allow the evaluation of a society's democratic status, as well as the existence of effective directly democratic rights. In other words, rights capable of exercising the principle. The constitutional project is performed daily and it requires the action of government, in all of its functions, since the execution of the Constitution is an obligation of all. When the effectiveness is left beside, its common to cogitate the transcription of rights about democracy in the Constitution. And once the thought of the Judiciary only as a law enforcer - liberal conception of the separation of powers - is overcame, the Judiciary assumes a role of rights creator in an interpretationist aspect. That's when the discussion about the limits of interpretation and judicial review techniques in the effectiviness of democracy comes to surface. In other words, the discussion that envolves the bond that separates creative interpretation from interpretative creation, as the technicalrational mode used by the Judiciary to accomplish the democractic principle. Either way, it becomes essential the detailed analysis of the form of interpretation adopted, as a way to never left aside the rationaily duty that should permeate judicial decision. The goal is not to deny the obvious creative process of Judiciary, but to understand its function so its exercise never exceeds the reasonable interpretation of fundamental precepts.
\end{abstract}

Keywords: Democracy. Judicial review. 


\section{INTRODUÇÃO}

A democracia, conforme consagrada nas Cartas Constitucionais contemporâneas, não se consubstancia unicamente a determinar modo de eleição dos representantes, mas sim a indicar vetores políticos, econômicos, sociais e culturais a que aspira a sociedade.

Nesse sentido, a atuação dos Tribunais Constitucionais para efetivar a democracia, seja num aspecto processual/procedimental, seja numa vertente material/substancial, significa, em última análise, a efetivação dos direitos fundamentais de uma sociedade e a realização dos objetivos dirigentes daquele Estado.

Para tanto, imprescindível o estudo do ativismo judicial nesse intuito para compreender de que forma as Cortes Constitucionais constroem as diretrizes hermenêuticas que irão resultar no aspecto prático da democracia.

As técnicas de controle de constitucionalidade, nesse sentido, prestam inegável benessse para a finalidade proposta, eis que se amoldam à necessidade do direito. É a tutela jurisdicional a serviço do direito material.

Assim, compreender os conceitos de democracia, as finalidades do Estado Constitucional, o papel das Cortes Constitucionais, e a forma com que tais Tribunais atuam em defesa do primeiro, acaba contribuindo para a efetivação deste direito considerado, por alguns, de quarta geração.

De fato, as atuações destas Cortes e as técnicas de controle que se utilizam para tanto acabam se tornando palpáveis no cotidiano da sociedade. É o que ocorre, por exemplo, quando o Supremo Tribunal Federal decide pela não aplicação de uma reforma eleitoral sobre inelegibilidade ou quando o Tribunal Superior Eleitoral praticamente legisla sobre a temática do caráter nacional dos partidos políticos.

Por essa razão, o estudo proposto, muito além de estudar limites, diretrizes hermenêuticas e técnicas processuais, acaba recaindo na própria materialidade da democracia, o que culmina com a satisfação ou não de direitos fundamentais, como o regime democrático ou o pluralismo político, inscritos em diversas Constituições pósmodernas.

Embora, a essência da democracia deve ser atribuída ao célebre discurso de Lincoln sobre o povo, o projeto democrático, no entanto, deve ser buscado muito 
antes, nas suas raízes gregas - democracia ateniense -, embora com características mais restritas e censitárias. A grande marca da democracia moderna, todavia, é um recorte artificioso entre direitos civis, políticos e sociais, distinção não realizada pelos gregos.

Ao longo do primeiro capítulo, discorremos acerca de algumas interpretações críticas e construtivas da democracia, como a concepção de Sartori no sentido de um governo pautado na opinião pública ${ }^{1}$; a ideia de cenário beligerante de Adam Przeworski ${ }^{2}$ e a insegurança eleitoral; as "poliarquias" e seus graus de Robert Dahl a depender, basicamente, da possibilidade de participação popular e do grau de oposição permitido ${ }^{3}$.

De uma forma geral, é comum relacionar a democracia à ideia de liberdade. Uma liberdade que permite, de forma plural, o desenvolvimento integral dos cidadãos e a "participação crítica no processo político em condições de igualdade económica, política e social"4.

A democracia, não obstante, é um regime delicado, que se apresenta extremamente exigente com a sociedade, com as instituições e com o poder e seus detentores. Das instituições exige estabilidade e respeito. Dos detentores do poder exige o atendimento do jogo pendular. Do povo exige, para a eleição dos representantes, um sufrágio com assepsia, puro, preservado do ambiente e dos fatores de poluição eleitoral que contaminam a vontade eleitoral manifestada pelo voto depositado na urna. E requer da oposição responsabilidade - o controle da atuação governamental deve ser realizado neste molde.

Essa concepção, incrivelmente dimensionada no século XX, sobretudo a partir da ideia de "deusa democracia", conduziu a uma inegável cobrança do Poder Público não apenas para se efetivar a democracia, mas para se manter um quadro que, ao mesmo tempo beligerante, pudesse oferecer a segurança das instituições, mais no sentido de sua liberdade.

Evidente que por ser um projeto constitucional ${ }^{6}$, nada mais natural que se incumbisse também ao Judiciário o poder-dever de zelar pela democracia, enquanto um

\footnotetext{
${ }^{1}$ SARTORI, Giovanni. Teoria de la democracia.

2 PRZEWORSKI, Adam. Transition to Democracy. Ainda: CAGGIANO, Monica Herman Salem. Oposição na Política.

${ }^{3}$ DAHL, Robert. Polyarchy - Participation and Opposition.

${ }^{4}$ CANOTILHO, José Joaquim Gomes. Direito constitucional e Teoria da Constituição. p. 289.

${ }^{5}$ GICQUEL, Jean, Droit Constitutionnel et Institutions politiques. p.185.

6 "A democracia é, no sentido constitucional, democratização da democracia". CANOTILHO, José Joaquim Gomes. Direito constitucional e Teoria da Constituição. p.290.
} 
direito fundamental para a própria existência do Estado e para o exercício da liberdade da sociedade.

Inegável, por outra via, que o grande pilar de desenvolvimento da democracia seja a representação política, dado o caráter de impossibilidade de seu exercício direto. Apesar de a representação ser elevada ao posto de uma grande conquista da humanidade, hodiernamente, não mais se contenta com isso, buscando um grau mais elevado de participação do povo na produção das decisões políticas.

E essa participação se vê justamente nos instrumentos adicionais da democracia, principalmente na via do controle do poder. É aí que se insere o Poder Judiciário e seu controle de constitucionalidade, sem mencionar a participação direta em casos específicos como o referendo, o plebiscito e o recall.

A Constituição é idealizada como mecanismo de limitação do poder político $^{7}$. Sob este aspecto, vem timbrada com a garantia da presença e da perpetuidade das instituições. É verdade que o constitucionalismo admite a ideia de que as Constituições não são para sempre, não podendo conduzir ao fenômeno da "fossilização da Constituição" . Mas, por outro lado, não esconde que a alteração constitucional nesse cenário envolve um processo complexo, a fim de garantir as instituições e a decisão política fundamental ${ }^{9}$.

Nesse novo contexto, as Constituições passam a albergar novos direitos, até de $4^{\mathrm{a}}$ e $5^{\mathrm{a}}$ dimensão, que transformam a postura do Estado e dos detentores do poder político. Dentre eles, menciona-se expressamente a democracia ${ }^{10}$.

Há também uma textura diferenciada, com normas de preceitos abertos, ao lado de normas não auto-executórias, incompletas ou programáticas. A própria Constituição atribui a outros poderes a tarefa de incrementar o dispositivo constitucional. A Justiça Constitucional, que num primeiro instante caracterizava-se como defensiva, assume, a partir da difusão do judicial review, uma posição de garante

\footnotetext{
${ }^{7}$ FERREIRA FILHO, Manoel Gonçalves. Curso de Direito Constitucional.

${ }^{8}$ Além disso, a maioria da doutrina se concentra na opinião de que o poder constituinte originário não encontra limites imanentes. Karl Loewenstein fala em "petrificação da Constituição". Teoria de la constitución. p. 164 e seguintes.

9 "Há que se considerar, no entanto, que as idéias de limitação do poder, de preservação dos direitos humanos e de prefixação da decisão política fundamental, o cerne fixo de uma Constituição, conduzem, na leitura de alguns analistas, a exemplo de Stephen Holmes, a identificar na Constituição uma postura antidemocrática, na medida em que engessa decisões futuras a que as novas gerações, numa democracia, deveriam ter assegurada a acessibilidade". CAGGIANO, Monica Herman Salem. Democracia $x$ constitucionalismo.

${ }^{10}$ BONAVIDES, Paulo. Curso de direito constitucional. p.571-572.
} 
da Constituição, orientando a decisão política. Há um nítido alargamento do campo de atuação jurisdicional.

Esse papel que decorre do contexto axiológico da Constituição acaba atribuindo ao Judiciário o inegável papel de "guardião da democracia" 11 . E, embora não se deva afirmar que a efetivação da democracia exige apenas papéis políticos ativos, é válida a observação de Robert Alexy: "Em ningún outro ámbito es tan clara la conexión entre el resultado jurídico y las valoraciones generales prácticas o políticas"12.

O professor Cass Sunstein faz a seguinte análise:

Também parece que a demasiado alardeada oposição entre o constitucionalismo e a democracia, ou entre os direitos e a democracia, tende, pois, a se dissolver inteiramente. Muitos direitos são indispensáveis para a democracia e para a deliberação democrática. Se nós protegemos tais diretos por meio da Constituição, nós não comprometemos o governo autônomo de nenhuma forma. Pelo contrário, o governo autônomo depende para sua existência dos direitos democráticos firmemente protegidos. $\mathrm{O}$ constitucionalismo pode assim garantir as pré-condições para a democracia limitando o poder das maiorias em eliminar aquelas pré-condições ${ }^{13}$.

Mas essa nova diretriz, longe de ser uma prerrogativa brasileira, deita suas raízes no Tribunal Constitucional Federal da Alemanha, conforme preleciona Leonardo Martins, tratando do Bundesverfassungsgericht (BVerfG), a qual atribui especial atividade quando a instância política preferiu se omitir, culminando por transferir questões políticas para o crivo do controle de constitucionalidade ${ }^{14}$.

Nota-se, assim, que essa nova perspectiva acentuou-se ainda mais com a omissão do legislador em certas temáticas consideradas cruciais para o Estado, dentre elas as questões atinentes à democracia ${ }^{15}$.

\footnotetext{
${ }^{11}$ HOLMES, Stephen. El Precompromisso Y La Paradoja de La Democracia. p. 219.

${ }^{12}$ ALEXY, Robert. Teoria de los derechos fundamentales. p.427. No vernáculo: "Em nenhum outro âmbito é tão clara a conexão entre o resultado jurídico e as valorações gerais, práticas ou políticas". Em outra ocasião, Alexy faz a seguinte ponderação: "A proposição fundamental: 'Todo o poder estatal provém do povo' exige conceber não só o parlamento como, ainda, o tribunal constitucional como representação do povo. O parlamento representa o cidadão politicamente, o tribunal constitucional, argumentativamente. Com isso, deve ser dito que a representação do povo pelo tribunal constitucional tem um caráter mais idealístico do que aquela pelo parlamento (...) A representação argumentativa dá bom resultado quando o tribunal constitucional é aceito como instância da reflexão do processo político". Constitucionalismo discursivo. p.53-54.

${ }^{13}$ SUNSTEIN, Cass R. A Constituição parcial. p.181-182.

${ }^{14}$ MARTINS, Leonardo. Direito processual constitucional alemão. p.5.

15 "A influência dos grupos de pressão sobre o legislador, o déficit de racionalidade identificado no processo legislativo e a possibilidade de que as decisões majoritárias do corpo legislativo venham a lesar direitos de minorias consistem elementos denotadores de uma mudança do papel desempenhado pela lei
} 
Leonardo Martins, citando Hillgruber e Goos, acentua a legitimidade e a legalidade de a minoria levar ao Tribunal Constitucional a decisão que fora tomada pela maioria, anteriormente, no âmbito político, de forma a conferir-lhe uma aprovação ou desaprovação a partir da hermenêutica constitucional: "De resto é legal e legítimo, do ponto de vista constitucional, que uma minoria parlamentar que é fraca no processo legislativo parlamentar tente transformar a derrota política sofrida em Berlim em uma vitória jurídica em Karlsruhe"16.

Em mesma linha, é do douto professor Jorge Miranda a seguinte observação:

Em estritos termos jurídicos, a legitimidade de um Tribunal Constitucional ou de órgão homologo não é mais nem menos do que a dos órgãos políticos: advêm da Constituição. E, se esta deriva de um poder constituinte democrático, então ela há-de ser, natural e forçosamente, uma legitimidade democrática ${ }^{17}$.

A mesma razão que fundamenta o raciocínio, no entanto, deve limitar a abrangência da construção. Não é demais lembrar que esse tipo de controle por parte do Judiciário exige ponderação e razoabilidade, a fim de garantir a autonomia na fixação de regras gerais por parte do Legislativo, mandatário do poder para tais questões ${ }^{18}$. É um problema tipicamente de limites para separação de poderes, ou de conformidade dos freios e contrapesos.

Aliás, muito se fala, ao tratar da temática do ativismo judicial, acerca da jurisdicionalização da política, no sentido de que, ao realizar o controle, o Judiciário estaria agindo como verdadeiro legislador, invadindo a esfera de atuação deste. Oscar Vilhena Vieira fala, ainda, numa maximização da questão, em "supremocracia"19.

Num primeiro momento, no entanto, a questão parece ser mais de efetivação da Constituição, poder conferido inclusive ao Supremo, do que em uma suposta “tomada de poder". É que quando se sente atingido em sua função o Legislativo

nos modernos sistemas constitucionais". MENDES, Gilmar Ferreira. Direitos fundamentais e controle de constitucionalidade. p.400. Ainda: “Até mesmo na atualidade, sob a proteção da Constituição de 1988 - a Constituição dita cidadã -, que ampliou de modo intenso a participação política, quer alargando o corpo eleitoral, como já exposto, quer pela inserção de mecanismos de interferência direta no pólo do poder, resta ainda prejudicada a figura do cidadão eleitor, demandando-se, pois, ações precisas no sentido de assegurar ao cidadão brasileiro, na sua plenitude, a possibilidade de alcançar esse status". CAGGIANO, Monica Herman Salem. Direito parlamentar e direito eleitoral. p.94.

${ }^{16}$ MARTINS, Leonardo. Direito processual constitucional alemão. p.16.

${ }^{17}$ MIRANDA, Jorge. Teoria do Estado e da Constituição. p.508.

${ }^{18}$ MARTINS, Leonardo. Direito processual constitucional alemão. p. 21.

${ }^{19}$ VIEIRA, Oscar Vilhena. Supremocracia.p.441. 
reage negativamente à atuação do Tribunal Constitucional, vide o caso da verticalização das coligações partidárias e a Emenda Constitucional 52/2006.

Ao depois, há que se ressaltar que o neoconstitucionalismo ressaltou a ideia de uma prevalência da Constituição, no sentido não mais apenas político, mas como "norma suprema e de fundamento de validade de todo o ordenamento jurídico". Os perigos de desvio, evidente preço da democracia e do constitucionalismo, devem ser remediados pela doutrina interpretativa que se associe à Teoria da Constituição, ao Direito Constitucional e à Teoria do Estado ${ }^{20}$.

Dentre as técnicas que têm sido utilizadas para o controle de constitucionalidade para efetivação da democracia destaca-se a interpretação conforme a Constituição - verfassungskonforme Auslegung, alternando enquanto princípio interpretativo ${ }^{21}$ ou como técnica.

A interpretação conforme a Constituição acaba servindo de subsídio não apenas para deixar de declarar inconstitucional lei que o seja, como na acepção de Thomas Cooley: "The court, if possible, must give the statute such a construction as will enable it to have effect" ${ }^{, 22}$. Mas também, e aqui sobreleva sua função interpretativa, para afirmar que é constitucional justamente por ser interpretado conforme a Constituição.

Mendes, Coelho e Branco apenas ressaltam, citando Carlos Alberto Lúcio Bittencourt, que a interpretação conforme a Constituição apenas deve ser admitida se não se traduzir em violência contra a expressão literal do texto ou não alterar o significado do texto por meio de mudança radical da concepção original do legislador $^{23}$ - aqui sim o Judiciário estaria confiscando a função legislativa de seu detentor legítimo.

\footnotetext{
${ }^{20}$ MENDES, Gilmar Ferreira; COELHO, Inocêncio Mártires; BRANCO, Paulo Gustavo Gonet. Curso de Direito Constitucional. p.129.

21 "Instrumento situado no âmbito do controle de constitucionalidade e não apenas uma simples regra de interpretação - como o STF enfatizou em decisão exemplar -, o princípio da interpretação conforme a Constituição consubstancia essencialmente uma diretriz de prudência política ou, se quisermos, de política constitucional, além de reforçar outros canônes interpretativos, como o princípio da unidade da Constituição e o da correção funcional”. MENDES, Gilmar Ferreira; COELHO, Inocêncio Mártires; BRANCO, Paulo Gustavo Gonet. Curso de direito constitucional. p.119.

${ }^{22}$ COOLEY, Thomas M. A treatise on the constitutional limitations. p.228. No vernáculo: "A Corte, se possível, deve dar à lei uma interpretação que lhe garanta a eficácia".

${ }^{23}$ MENDES, Gilmar Ferreira; COELHO, Inocêncio Mártires; BRANCO, Paulo Gustavo Gonet. Curso de direito constitucional. p.1257.
} 
Não se pode olvidar, além disso, da declaração de nulidade total, da declaração de nulidade parcial e da declaração de nulidade parcial sem redução de texto, enquanto efeitos da decisão.

Na discussão acerca da constitucionalidade da "cláusula de barreira à brasileira" ${ }^{24}$, por exemplo, o esforço hermenêutico do Supremo Tribunal Federal partiu do pressuposto de que tais restrições ofenderiam o pluralismo político, a autonomia partidária, a soberania nacional, o regime democrático, o pluripartidarismo, os direitos fundamentais da pessoa humana e a representação das minorias nas Mesas e Comissões permanentes da Câmara e do $S^{2} n a d o{ }^{25}$, para declarar os artigos da Lei 9.096/95 que tratavam da cláusula parcial ou totalmente nulos.

$\mathrm{Na}$ ADI 3.592, que atacava a vedação da captação de sufrágio prevista no artigo 41-A da Lei 9.504/97, o Supremo, sobrelevando a concepção de voto livre como garantia da democracia, entendeu constitucional o dispositivo atacado não apenas no aspecto formal - o que foi atacado pelo PSB -, mas também como ideal para o próprio princípio democrático, "verdadeira profilaxia ético-cívica"26. Nesse caso, ao declarar a constitucionalidade, o STF, outra vez, acabou conferindo máxima efetividade.

$\mathrm{O}$ fato é que na contemporaneidade, o jurídico não mais pode ser dissociado do político, nem menos obrigado ao exercício político do poder, como obrigaria uma postura montesquiana. É de Ovídio Baptista a observação que segue:

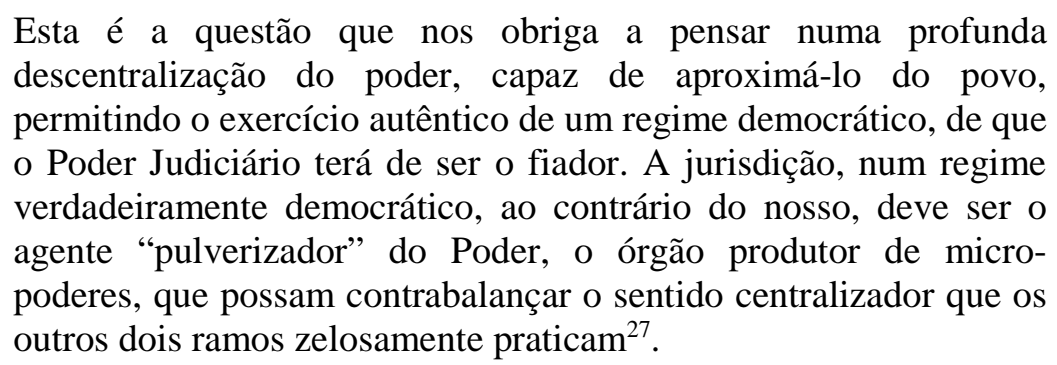

E é evidente que a operacionalização do princípio democrático, longe de ser tarefa meramente legislativa, acaba sendo incumbência de todas as funções do Estado, inclusive para suprir eventuais omissões ou para corrigir incorreções das demais.

\footnotetext{
${ }^{24}$ MENDES, Gilmar Ferreira; COELHO, Inocêncio Mártires; BRANCO, Paulo Gustavo Gonet. Curso de direito constitucional. p.751.

${ }^{25}$ ADIs 1.351 e 1.354 .

26 Voto do Ministro Ayres Britto.

${ }^{27}$ SILVA, Ovídio A. Baptista. Processo e ideologia. p.316.
} 
Cumpre ressaltar que um esforço que direcionará toda a nossa construção será sempre o de compreender os liames entre a pura criação judicial do Direito e a interpretação criativa a partir das diretrizes constitucionais. De forma a garantir o equilíbrio do Estado, a construção racional de uma interpretação razoável, de forma a não reverter o sentido da norma, deverá guiar o julgador em seu mister de desmistificar o problema democrático.

Essas são as principais questões a serem aprofundadas ao longo deste trabalho. 


\section{CONCLUSÃO}

A democracia é um conceito em eterna construção. O princípio democrático é um preceito em contínua efetivação.

As clássicas e modernas concepções de democracia não conseguem se refugiar em um lugar onde não caiba o povo predicado pela liberdade. Seja como for, parece-nos que a democracia transita em um lugar soberano que, embora inatingível em sua plenitude, fornece aos atores do círculo social a missão de concretizar a sua efetivação.

Przeworski fornece pistas condizentes com a necessidade de que a democracia pressupõe um cenário beligerante, isto é, em que se possibilita a participação para aqueles que estão fora do Poder terem condições de a ele voltar. O que também exige o atendimento das expectativas sociais para os que não querem deixar o mandato.

Dahl foi além, justamente pela invocação da existência conceitual de democracia plena apenas se houver plenitude nas vertentes possibilidade de participação popular e grau de oposição permitido.

Muitos teóricos políticos ressaltaram que o problema da participação encontra-se intrinsecamente vinculado à presença dos partidos políticos. Diga-se, aliás, consoante excelentes construções de Kelsen que os partidos políticos são imprescindíveis na revelação da vontade popular, servindo como meio para ofertar a transmissão dos anseios da sociedade. Até porque, conforme conhecido por Rousseau, uma democracia direta somente seria viável em pequenas sociedades ${ }^{410}$. Noutros modelos, serviria mais como atravancamento do sistema do que como voz da sociedade.

O século XX assistiu a "deusa democracia" ser elencada ao rol dos princípios fundamentais do Estado Constitucional, reconhecida como necessária para o estabelecimento do equilíbrio das funções do Estado. Mesmo as demais particularidades das novas Constituições - como o rol de direitos fundamentais - cresceram sob a égide de um objetivo democrático. Daí se dizer que a Constituição assevera um incontável número de direitos que circundam a democracia, dispostos a auxiliar a efetivação do princípio.

${ }^{410}$ CAGGIANO, Monica Herman Salem. Oposição na política. p. 36. 
Quando se fala em projeto constitucional, por evidente os teóricos do Estado sempre apontam uma consequência inerente à existência de uma diretriz duradoura. O problema de como o passado possa guiar o futuro, sem que no futuro se pretenda desviar dos objetivos do passado, mas tão somente articulá-los para oferecer respostas temporalmente mais adequadas sempre existiu e sempre existirá na temática do tempo do Direito.

Mais do que isso, questiona-se se o projeto democrático seria realmente eterno. Mas esse é um problema de base, visto que, se o Estado é uma ficção jurídica criada para organizar e direcionar a sociedade, isto é, o povo, nada mais natural e consequente do que o modelo que se apresenta leve em consideração a ampla participação popular, o que culmina na própria democracia. Assim, enquanto houver Estado Constitucional, a democracia lhe perseguirá.

Nesse novo paradigma do Estado, ao melhor modelo das revoluções científicas de $\mathrm{Kuhn}^{411}$, a defesa dos preceitos constitucionais de uma Constituição materialmente garantidora, apesar de requisitada de todos os Poderes do Estado, acabará encontrando no Judiciário seu fiel guardião. Assim, o Judiciário sai de uma posição prérevolucionária bastante amiúde e passiva para assumir no contexto contemporâneo o papel protagonista: a última palavra do Estado Constitucional.

Seja no judicial review ou no modelo kelseniano, a ideia que circunda o controle de constitucionalidade se apresenta da mesma forma: a necessidade de que o Judiciário garanta a supremacia da Constituição por meio do controle dos atos estatais inferiores a ela, restando, assim, assegurado o projeto constitucional de outrora, mas sempre pendente de mutações interpretativas.

Evidente que o esforço trará em si o risco do abuso, na medida em que os liames entre a interpretação jurisdicional e a legislação judiciária não se mostram sempre tão óbvios. Partindo da premissa de Kelsen, de que a tarefa do julgador sempre terá em si uma vertente criativa ${ }^{412}$, torna-se necessário delimitar até que ponto essa criação não adentra à esfera detidamente legislativa.

Essa preocupação é esposada por Cappelletti:

\footnotetext{
411 "uma teoria científica, após ter atingido o status de paradigma, somente é considerado inválida quando existe uma alternativa disponível para substituí-la (...) Decidir rejeitar um paradigma é sempre decidir simultaneamente aceitar outro e o juízo que conduz a essa decisão envolve a comparação de ambos os paradigmas com a natureza, bem como sua comparação mútua”. KUHN, Thomas. A estrutura das revoluções científicas. p. 108.

${ }^{412}$ KELSEN, Hans. Jurisdição constitucional. p. 124 e ss.
} 
Vimos que a criatividade constitui um fator inevitável da função jurisdicional, e que existem, por outro lado, importantes razões para o acentuado desenvolvimento de tal criatividade em nosso século, correspondendo a características e exigências fundamentais de nossa época, econômicas, políticas, constitucionais e sociais. Mas, em consequência dessas premissas, há neste ponto uma segunda questão a requerer resposta. Devemos inquirir se a atividade judiciária, ou sua mais acentuada medida, torna o juiz legislador; se, em outras palavras, assumindo os juízes (ou alguns deles, como os constitucionais e comunitários) papel acentuadamente criativo, a função jurisdicional termina por se igualar à legislativa, e os juízes (ou aqueles outros juízes) acabam por invadir o domínio do poder legislativo ${ }^{413}$.

Ainda, deve-se ressaltar que o controle de constitucionalidade traz ao Judiciário o papel de abordar temas que, por estarem materialmente inseridos na Constituição, não eram objeto de análise jurisdicional no direito pré-revolucionário, inclusive questões políticas tidas como inerentes à análise governamental ou de abrangência das atividades legislativas.

Tampouco se pode olvidar que, talqualmente a legislação, não há como afastar a identificação do conteúdo moral das decisões, seja pela formação ideológica do julgador, seja pela influência da confecção da norma, ou mesmo pelo fruto decorrente da interpretação realizada de forma não imune ao ambiente moral.

Diante desse quadro, alguns doutrinadores oferecem a saída da racionalização das decisões judiciais, de modo que os julgadores possam, na medida da construção jurisdicional, justificá-las sob a égide de fundamentos que ofereçam subsídio lógico-estrutural para os motivos determinantes, modelo bastante significativo diante de preceitos polissêmicos ou do embate de princípios constitucionais.

A despeito desse trabalho ter por foco as técnicas de controle de constitucionalidade utilizadas para a efetivação da democracia, esses estudos foram imprescindíveis para oferecer sustentáculos às nossas ponderações.

Na jurisprudência brasileira, a ascensão de preocupações tanto com um modelo mais participativo do controle de constitucionalidade, como com a efetivação do princípio democrático, conduziram à ampla participação não apenas da Corte Constitucional, mas, sobretudo, do Tribunal Superior Eleitoral, que, de forma didática, muitas vezes antecipava a posição a ser definida mais tarde pelo próprio Supremo.

\footnotetext{
${ }^{413}$ CAPPELLETTI, Mauro. Juízes legisladores? p. 73.
} 
Entre nós, as técnicas de controle, de forte influência alemã, muitas vezes apresentaram sugestões pouco ortodoxas diante da tese de nulidade das leis inconstitucionais, para estruturar preceitos que modificariam o pressuposto de que the inconstitutional statute is not law at all, como defendia Willoughby no judicial review norte-americano ${ }^{414}$.

Nesse contexto, nasceram teses de interpretação conforme a Constituição, precipuamente quando a declaração de nulidade fosse um mal maior do que remediar-se dentro da razoabilidade a interpretação do preceito. É o que o Bundesverfassgungsgericht exercitou com a redução do percentual de $5 \%$ para $0,5 \%$ no caso das cláusulas de barreira.

No Brasil, no entanto, a temática das cláusulas de barreira sofrera interpretação distinta, sendo-lhe preferível declarar nulidades totais e parciais. É que a interpretação conforme enquanto técnica de interpretação oferece o alto risco do Judiciário adentrar à discussão de cunho nitidamente legislativo. Mas, como se disse, houve momentos em que a declaração sem redução do texto foi também aplicável, considerando o fato de que o objetivo era simplesmente eliminar uma restrição temporal constante de um artigo.

Declarações de nulidade sem redução do texto, embora próximas da interpretação conforme, mostraram-se divergentes em sua definição, proporcionando resultados distintos, com a primeira mais restritiva do que a segunda.

A ausência das leis diante de mandamentos constitucionais sempre se apresentou como um problema renitente no Estado Constitucional, ainda mais após a mudança de paradigma que possibilitara às Cortes o ingresso em questões que outrora eram limitadas ao debate político.

A jurisprudência, ademais, demonstrou que, sempre chamado, quase sempre o Parlamento se mostra inerte à advertência, recalcitrante em sua omissão, deixando graves problemas da sociedade sem a devida regulação legislativa.

Nessas situações, a sociedade buscará nas Cortes o remédio, não mais para apenas advertir o Legislativo, mas também para sanar a omissão apontada, o que, se não realizado de forma cautelosa, indicará um atropelado ingresso do Judiciário na vida legislativa.

${ }^{414}$ WILLOUGHBY, Westel Woodbury. The constitutional law of the United States. p. 9-10. 
Como procuramos demonstrar, é evidente que os motes interpretacionistas podem conduzir a resultados diversos. E mesmo em face de quadros que exigem a justificação racional da construção jurisprudencial, não assusta a possibilidade ampla de entendimento do Judiciário, por vezes procurando conduzir sua motivação para alcançar a finalidade pressuposta.

Nesse ínterim, mostra-se ideal que a interpretação razoável ofereça algumas bases para que a interpretação, ao cabo, não ofereça solução completamente desvirtuada tanto do texto legal quanto do objetivo proposto de sua confecção, ainda que se valendo da necessidade de se adentrar ao mundo das mutações constitucionais.

Por fim, tivemos a oportunidade de adentrar à discussão que instaura a transcendência dos motivos determinantes nas ações concretas, o que significa, em última análise, a criação do precedente brasileiro, sobretudo em casos relevantes que trataram da discussão democrática.

Assim, tanto a inaplicabilidade da Lei de Ficha Limpa para as eleições de 2010, como sua constitucionalidade para a partir de então, tiveram discussões travadas em sede de recurso extraordinário, fornecendo um resultado para além das partes do processo.

Precipuamente nas temáticas democráticas, em face dos interesses difusos envolvidos e da sua objetividade em relação à estruturação do Estado, torna-se mais substancial a defesa de que decisões tomadas em sede incidental por uma Corte Constitucional devem ter aplicabilidade ampla.

A luta pela efetivação do princípio democrático traz em si mais do que a simples apuração de que se trata de um dever de todos. Oferecerá sempre o questionamento de quem exatamente e de que forma buscará implementar direitos que servem para estruturar a democracia.

Nesse diapasão, é natural que as dificuldades se apresentem, ainda mais considerando o embate de poderes, a possibilidade da quebra dos equilíbrios, a abertura dos preceitos e a ampla margem interpretativa.

A razoabilidade, a racionalidade e a utilização da técnica podem oferecer asfalto para que, nos dizeres do mestre Bonavides, se coloque a navegar "o barco constitucional" 415 .

\footnotetext{
${ }^{415}$ BONAVIDES, Paulo. A Constituição aberta. p. 243.
} 


\section{BIBLIOGRAFIA}

ACKERMAN, Bruce. Nós, o povo soberano. Belo Horizonte: Del Rey, 2006.

ALAIN. Mars ou la guerre jugée. Paris: Éditions Gallimard, 1936.

ALEXY, Robert. Constitucionalismo discursivo. Porto Alegre: Livraria do Advogado, 2007.

Teoria da argumentação jurídica: a teoria do discurso racional como teoria da justificação jurídica. São Paulo: Landy, 2001.

Teoría de los derechos fundamentales. Madri: Centro de Estúdios Políticos y Constitucionales. 2002.

AMADO, Gilberto. Eleição e representação. Brasília: Senado Federal, 1999.

AMANTINO, Antônio Kurtz. Democracia: a concepção de Schumpeter. Teoria e evidência econômica. Passo Fundo, v. 5, n. 10, p. 127-140, mai./1998

ANDRADE, José Carlos Vieira de. Os direitos fundamentais na Constituição Portuguesa de 1976. Coimbra: Livraria Almedina, 1998.

ARISTÓTELES. A política. Rio de Janeiro: Ediouro, 1965.

ARON, Raymond. Democracia e totalitarismo. Lisboa: Presença, 1966.

Ensayo sobre las libertades. Madrid: Alianza, 1969.

BACHRACH, Peter. Critica de la teoria elitista de la democracia. Buenos Aires: Amorrortu, 1973.

BAILEY, Sydney D. British parliamentary democracy. 3.ed. London: George H. Harrap \& Co. Ltd, 1971.

BARBOSA, Rui. O Direito do Amazonas ao Acre Setentrional. Rio de Janeiro: Typologia do Jornal do Commercio, 1910. vs. I e II.

BASTOS, Celso Ribeiro. Hermenêutica e interpretação constitucional. 2.ed. São Paulo: Celso Bastos Editor, 1999.

BAUDRILLARD, Jean. À sombra das maiorias silenciosas: o fim do social e o surgimento das massas. São Paulo: Brasiliense, 2004 
BAUMAN, Zygmunt. Legisladores e intérpretes: sobre modernidade, pós-modernidade e intelectuais. Rio de Janeiro: Zahar, 2010.

BEÇAK, Rubens. A hipertrofia do Executivo brasileiro: o impacto da Constituição de 1988. São Paulo: Faculdade de Direito da Universidade de São Paulo, 2007.

Reflexões sobre o evolver democrático rumo à sua otimização: a atualidade da "democracia deliberativa" e suporte teórico. Enfoque histórico-evolutivo.

Contribuição à Teoria Geral do Estado. 2013. 173f. Tese (Livre-Docência) - Faculdade de Direito, Universidade de São Paulo, São Paulo, 2013.

BOBBIO, Norberto. A teoria das formas de governo. Brasília: UnB, 1995.

. Liberalismo e democracia. São Paulo: Brasiliense, 1988.

. Qual socialismo? Rio de Janeiro: Paz e Terra, 1983.

Teoria Geral da Política: A Filosofia Política e as Lições dos Clássicos. Rio de Janeiro: Elsevier, 2000.

; MATTEUCI, Nicola; PASQUINO, Gianfranco. Dicionário de política. 2.ed. Brasília: UnB, 1986.

BONAVIDES, Paulo. A Constituição aberta: temas políticos e constitucionais da atualidade. Belo Horizonte: Del Rey, 1993.

Curso de direito constitucional. 22.ed. São Paulo: Malheiros, 2008.

. Do Estado liberal ao Estado social. 4.ed. Rio de Janeiro: Forense, 1980

BORGES DE OLIVEIRA, Emerson Ademir. A encruzilhada jurídica entre a "tradição" processual e a perspectiva fundamental dos direitos. Revista de Direito Público. Porto Alegre, n. 28, p. 19-40, 2009.

Ativismo judicial e o papel das Cortes Constitucionais nas correções de rota da crise da democracia representativa. Revista de Direito Público. Porto Alegre, n. 40, p. 25-49, 2011.

. O processo trabalhista e a coisa julgada inconstitucional: reflexos da Ação Declaratória de Constitucionalidade 16 na execução trabalhista. Revista de Direito Univille. Joinville, v.2, n.1, p. 58-67. 2012. 
Técnicas de controle de constitucionalidade e ativismo judicial na efetivação da democracia: notas introdutórias. Revista de Direito Público. Porto Alegre, n. 44, p. 174-189. 2012.

BULOS, Uadi Lâmego. Curso de direito constitucional. 5.ed. São Paulo: Saraiva, 2010. BURDEAU, Georges. A democracia. 3.ed. Lisboa: Publicações Europa-América, 1975. Traité de science politique. Paris: LGDJ, 1970. t.5.

CAGGIANO, Monica Herman Salem. Democracia x constitucionalismo: um navio à deriva? Cadernos de Pós-Graduação em Direito: estudos e documentos de trabalho, v.1, p-5-23, 2011.

. Direito parlamentar e direito eleitoral. Barueri: Manole, 2004.

. Oposição na política. São Paulo: Angelotti, 1995.

. Sistemas eleitorais x representação política. Brasília: Senado Federal, 1990.

CAMPOS, Rosana Soares. Escolhas políticas, decisões econômicas, consequências sociais: um estudo sobre os impactos da democracia procedimental e do neoliberalismo na América Latina e no Brasil. 247f. Tese (Doutorado em Ciência Política) - Instituto de Filosofia e Ciências Humanas, UFRGS, Porto Alegre, 2010.

CANOTILHO, José Joaquim Gomes. Direito Constitucional e Teoria da Constituição. 7.ed. Coimbra: Almedina, 2007.

CAPPELLETTI, Mauro. Juízes legisladores? Porto Alegre: Sérgio Antonio Fabris Editor, 1999.

CARROZZA, Paolo; GIOVINE, Alfonso di; FERRARI, Giuseppe F. Diritto costituzionale comparato. Roma: Editori Laterza, 2009.

CARVALHO FILHO, José dos Santos. Manual de Direito Administrativo. 22.ed. Rio de Janeiro: Lumen Juris, 2009.

CLÈVE, Clemerson Marlin. Fidelidade partidária. Curitiba: Juruá, 1999.

COELHO, Fábio Ulhoa. Hermenêutica Kelseniana. In: Direito, Cidadania e Justiça.

São Paulo: Revista dos Tribunais, 1995. 
COOLEY, Thomas M. A treatise on the constitutional limitations: which rest upon the legislative power of the States of the American Union. 7.ed. Boston: Little Brown, 1903.

DAHL, Robert A. How democratic is the American Constitution? New Haven/London: Yale University Press, 2001.

. Poliarquia e oposição. São Paulo: Editora USP, 2005.

. Polyarchy - Participation and Opposition. 4.ed. New Haven: Yale University Press, 1973.

DALLARI, Dalmo de Abreu. Elementos de Teoria Geral do Estado. 24.ed. São Paulo: Saraiva, 2003. . O que é participação política. São Paulo: Brasiliense, 1983.

DIDIER JUNIOR, Fredie. Transformações do recurso extraordinário. In: FUX, L.; NERY JR, N.; WAMBIER, T. A. A. (Coords.). Processo e Constituição: estudos em homenagem ao professor José Carlos Barbosa Moreira. São Paulo: Revista dos Tribunais, 2006.

DINIZ, Maria Helena. Norma constitucional e seus efeitos. São Paulo: Saraiva, 1989.

DUVERGER, Maurice. Institutions Politiques et Droit Constitutionnel. Paris: PUF, 1971.

. Os partidos politicos. Rio de Janeiro: Zahar Editora, 1970.

EHRMANN, Henry W. Democracy in a changing society. New York: Frederick A. Praeger, 1964.

ELY, John Hart. Democracia e desconfiança: uma teoria do controle judicial de constitucionalidade. São Paulo: Editora WMF Martins Fontes, 2010.

FERREIRA FILHO, Manoel Gonçalves. A democracia no limiar do século XXI. São Paulo: Saraiva, 2001.

. A democracia possível. 2.ed. São Paulo: Saraiva, 1974.

A reconstrução da democracia: ensaio sobre a institucionalização da democracia no mundo contemporâneo e em especial no Brasil. São Paulo: Saraiva, 1979.

Curso de direito constitucional. 25.ed. São Paulo: Saraiva, 1999. 
. Estado de Direito e Constituição. 4.ed. São Paulo: Saraiva, 2007.

. Sete vezes democracia. São Paulo: Convívio, 1977.

GICQUEL, Jean. Droit Constitutionnel et Institutions politiques. 18.ed. Paris:

Montchrestien, 2002.

GILMORE, Grant. As eras do direito americano. Rio de Janeiro: Forense Universitária, 1978.

GOLDSWORTHY, Jeffrey. The sovereignty of parliament. New York: Oxford University Press, 1999.

GRAU, Eros Roberto. A constituinte e a constituição que teremos. São Paulo: Revista dos Tribunais, 1985.

HÄBERLE, Peter. Hermenêutica constitucional: A sociedade aberta dos intérpretes da Constituição: contribuição para a interpretação pluralista e "procedimental" da

Constituição. Porto Alegre: Sérgio Antonio Fabris Editor, 1997.

Pluralismo y Constitución. Madrid: Editorial Tecnos, 2002.

HARTWIG, Matthias. El control político en Alemania. In: MAILLARD, José Luis Prado et alli (Org.). El control político en el Derecho comparado. Granada: Editorial Comares, 2010. p.93-110.

HEGEL, Georg Wilhelm Friedrich. Princípios de filosofia do direito. São Paulo: Martins Fontes, 1997.

HESSE, Konrad. A força normativa da Constituição. Porto Alegre: Sérgio Antonio Fabris Editor, 1991.

HOBSBAWM, Eric. Era dos Extremos: O breve século XX: 1914-1991. 2.ed. São Paulo: Companhia das Letras, 1995.

HOFSTADTER, Richard. Great Issues in American History. New York: Vintage Books, 1958.

HOLMES, Stephen. El Precompromisso y la paradoja de la democracia. In: ELSTER, Jon; SLAGSTAD, Rune (Org.). Constitucionalismo y democracia. México: Colegio Nacional de Ciências Políticas Y Administración Pública, A. C. e Fondo de Cultura Económica, 1999.

; SUNSTEIN, Cass R. The Cost of Rights: Why liberty depends on taxes.

Nova Iorque: W.W. Norton \& Company, Inc., 1999. 
HOURQUEBIE, Fabrice. Quelques observations sur l'emergence du contre-pouvoir jurisdictionnel en France. Cadernos de Pós-Graduação em Direito: estudos e documentos de trabalho, n.15, 2012.

JEFFERSON, Thomas. On democracy. New York: Penguin Books, Inc., 1946.

KELSEN, Hans. A democracia. São Paulo: Martins Fontes, 1993.

. Esencia y valor de la democracia. Barcelona: Editorial Labor, 1934.

Jurisdição constitucional. 2.ed. São Paulo: Martins Fontes, 2007.

. O Estado como integração: um confronto de princípios. São Paulo: Martins Fontes, 2003.

Teoria geral das normas. Porto Alegre: Sérgio Antonio Fabris Editor, 1986.

Teoria Pura do Direito. 6.ed. São Paulo: Martins Fontes, 1998.

KUHN, Thomas. A estrutura das revoluções científicas. 5. Ed. São Paulo: Perspectiva, 1997.

LASSALE, Ferdinand. ¿Qué es una Constitucion? Madrid: Editorial Cenit, 1931.

LOEWENSTEIN, Karl. Teoría de La Constitución. 2.ed. Barcelona: Ediciones Ariel, 1970.

MALBERG, R. Carre de. Teoria general Del Estado. Ciudad de México: Fondo de Cultura Economica, 1948.

MAQUIAVEL, Nicolau. O Príncipe. 11.ed. São Paulo: Bertrand Brasil, 1986.

MARINONI, Luiz Guilherme. Curso de processo civil. São Paulo: Revista dos Tribunais, 2006. v.1: Teoria geral do processo.

Precedentes obrigatórios. São Paulo: Revista dos Tribunais, 2010.

; ARENHART, Sérgio Cruz. Curso de processo civil. 6.ed. São Paulo:

Revista dos Tribunais, 2007. v.2.

; Curso de processo civil. São Paulo: Revista dos Tribunais, 2007. v. 3. 
MARINONI, Luiz Guilherme; MITIDIERO, Daniel. Repercussão geral no Recurso Extraordinário. São Paulo: Revista dos Tribunais, 2007.

MARSHALL, John. Decisões constitucionais de Marshall. Brasília: Ministério da Justiça, 1997.

MARTINS, Leonardo. Direito Processual Constitucional Alemão. São Paulo: Atlas, 2011.

MELLO, Leonel Itaussu A.; COSTA, Luís César Amad. História moderna e contemporânea. 6.ed. São Paulo: Scipione, 1996.

MENDES, Gilmar Ferreira. Controle abstrato de constitucionalidade: ADI, ADC e ADO: comentários à Lei n. 9.868/99. São Paulo: Saraiva, 2012.

. Controle de constitucionalidade: aspectos jurídicos e políticos. São Paulo: Saraiva, 1990.

. Direitos fundamentais e controle de constitucionalidade. 3.ed. São Paulo:

Saraiva, 2007.

Jurisdição constitucional: o controle abstrato de normas no Brasil e na Alemanha. 2.ed. São Paulo: Saraiva, 1998.

. Moreira Alves e o controle de constitucionalidade no Brasil. São Paulo:

Saraiva, 2004.

. O significado da liberdade de imprensa no Estado Democrático de Direito e seu desenvolvimento jurisprudencial pelas Cortes Constitucionais: breves considerações. Observatório da Jurisdição constitucional. Brasília: IDP, ano 4, 2010/2011.

; COELHO, Inocêncio Mártires; BRANCO, Paulo Gustavo Gonet. Curso de Direito Constitucional. 3.ed. São Paulo: Saraiva, 2008.

MIRANDA, Jorge. Teoria do Estado e da Constituição. 3.ed. Rio de Janeiro: Forense, 2011.

MIRANDA, Pontes de. Comentários à Constituição de 1967. São Paulo: Revista dos Tribunais, 1967. t.III.

MONTESQUIEU, Charles-Louis de Secondat. Do Espírito das Leis. São Paulo:

Difusão Europeia do Livro, 1962. 
MORAES, Alexandre de. Direito Constitucional. 28.ed. São Paulo: Atlas, 2012.

MOSCA, Gaetano; BOUTHOUL, Gaston. História das doutrinas políticas. 6.ed. Rio de Janeiro: Zahar Editores, 1983.

NEVES, Marcelo. A constitucionalização simbólica. São Paulo: WMF Martins Fontes, 2007.

NUN, José. Democracia: ¿Gobierno del pueblo o gobierno de los políticos? 2.ed.

México: Fondo de Cultura Económica, 2002.

OLIVEIRA, Bruno Batista da Costa de. A relação entre soberania popular e governo democrático na filosofia política de Jean Jacques Rousseau. Revista de Direito Constitucional e Internacional. São Paulo, n. 73, p. 35-59. 2010.

OST, François. O tempo do Direito. Bauru: EdUSC, 2005.

O’BRIEN, David M. Constitutional Law and Politics. New York: W. W. Norton, 1991. v.2: Civil Rights and Civil Liberties.

. Storm Center: The Supreme Court in American Politics. New York: W. W. Norton, 1986.

PLATÃO. A República. São Paulo: Nova Cultural, 1997.

Diálogos: Fédon, Sofista e Político. Rio de Janeiro: Ediouro, s.d.

POPPER, Karl. Popper on Democracy: The open society and its enemies revisited. The economist. New York, p. 25 e ss, 23 abr. 1988.

PRZEWORSKI, Adam. Sustainable democracy. Cambridge: Cambridge University Press, 1995.

Transition to Democracy. Cambridge: Cambridge University Press, 1991.

RADBRUCH, Gustav. Filosofia do direito. Coimbra: Arménio Amado Ed., 1961. v.1.

ROTHENBURG, Walter Claudius. Direito constitucional. 1.ed. São Paulo: Verbatim, 2010.

ROUSSEAU, Jean-Jacques. O contrato social. Rio de Janeiro: Ediouro, s.d.

RUFFIA, Paolo Biscaretti Di. Introduzione al Diritto Costituzionale Comparato. 3.ed. Milão: Dott. A. Giuffrè Ed., 1974. 
SARLET, Ingo Wolfgang. A eficácia dos direitos fundamentais. 2.ed. Porto Alegre: Livraria do Advogado, 2001.

SARTORI, Giovanni. A teoria da democracia revisitada: o debate contemporâneo. São Paulo: Editora Ática, 1994. v. 1.

Teoria de la democracia. Madrid: Alianza Universidad, 1987.

SCHMITT, Carl. A crise da democracia parlamentar. São Paulo: Scritta, 1996.

Legalidad y legitimidad. Madrid: Aguilar, 1971.

SCHUMPETER, Joseph A. Capitalism, socialism and democracy. 2.ed. New York and London: Harper \& Brothers Publishers, 1947.

. Capitalismo, socialismo e democracia. Rio de Janeiro: Zahar, 1984.

SILVA, José Afonso da. Curso de direito constitucional positivo. 30.ed. São Paulo: Malheiros, 2008.

SILVA, Ovídio A. Baptista. Processo e ideologia: o paradigma racionalista. 2.ed. Rio de Janeiro: Forense, 2006.

STERN, Klaus. Das Staatsrecht des Bundesrepublik Deutschland. Munique: Allgemeine Lehren der Grundrechte, 1989. v.III/1.

SUNSTEIN, Cass R. A Constituição parcial. Belo Horizonte: Del Rey, 2009.

TAFT, William Howard. Hearings before the House Committee on the Judiciary. 67th Congress, 2d sess., 1922, 2.

TAVARES, André Ramos. Fronteiras da Hermenêutica Constitucional. São Paulo: Método, 2006.

TEMER, Michel. Elementos de direito constitucional. 14.ed. São Paulo: Malheiros, 1998.

THOMA, Richard. Die juristische Bedeutung der Grundrechtliche Sätze der deustchen Reichsverfassung im Allgemeinen. In: NIPPERDEY, Hans Carl (Org.) Die Grundrechte und Grundpflichten der Reichsverfassung. Berlim: Reimar Hobbing, 1929. v.I.

TUCÍDIDES. História da guerra do Peloponeso. 4.ed. Brasília: UnB, 1987. 
VIEIRA, Oscar Vilhena. Supremocracia. Revista de Direito da Fundação Getúlio Vargas, São Paulo, n. 8, p. 441-464, jul/dez 2008.

VILANOVA, Lourival. As estruturas lógicas e o sistema do direito positivo. 2.ed. São Paulo: Max Limonad, 1997.

VIOLA, Francesco. La democracia deliberativa entre constitucionalismo y multiculturalismo. México: Universidad Nacional Autônoma de México, 2006.

WILLOUGHBY, Westel Woodbury. The constitutional law of the United States. New York: Baker, Voorhis, 1910. v.1. 